\title{
Iniciativa Para Integração Da Infraestrura Regional Sul-americana (IIRSA): Considerações preliminares sobre objetivos, atores e escalas de ação
}

\author{
Eduarda Figueiredo Scheibe
}

Mestranda do Programa de Pós-Graduação em Geografia da Universidade Federal do Rio Grande do Sul, Porto Alegre.

Recebido em 01/2012. Aceito para publicação em 04/2012.

Versão online publicada em 17/11/2012 (http://seer.ufrgs.br/paraonde)

\begin{abstract}
Resumo - 0 presente artigo tem por objetivo delinear algumas considerações preliminares importantes para a análise de processos de integração regional internacional, desenvolvidas a partir de noções tais como a de "transversalidade espacial", o "binômio" universalismo-relativismo e a correlação "açãoterritorialização". Acredita-se, entretanto, que a reflexão desenvolvida com foco no processo sulamericano e, mais especificamente, na iniciativa para Integração da Infraestrutura Regional SulAmericana, pode também ser útil na pesquisa sobre políticas territoriais em geral, com elaboração e resultados em múltiplas escalas.
\end{abstract}

Palavras-chave: IIRSA. Integração Sul-americana. Transversalidade Espacial. Universalismorelativismo. Ação-territorialização.

\section{Introdução}

O caminho da pesquisa tem como ponto de partida uma pergunta. Formulado o questionamento principal, este estimulará o pesquisador a encontrar as ferramentas necessárias para respondê-lo: desenhar uma sucessão de etapas que, idealmente, esclarecerá o funcionamento, o direcionamento e/ou a solução para o problema posto. Frequentemente, este "desenho de pesquisa" é composto por outras perguntas, que desvelam considerações preliminares que devem ser feitas previamente à resposta final - no sentido de uma resposta última, com certeza não necessariamente definitiva.

É natural que a pergunta que norteia qualquer estudo seja mais satisfatoriamente respondida por um ramo específico da ciência do que por outros. A categorização restrita, entretanto, tem o potencial de limitar também a capacidade de resposta da pesquisa empreendida. 0 objeto aqui explorado, qual seja, a integração regional sulamericana, mais especificamente, a iniciativa para Integração da Infraestrutura Regional Sul-Americana, é apenas um exemplo de tópico que pode suscitar perguntas com os direcionamentos mais variados, com ênfase maior ou menor em problemas econô- micos, políticos, geopolíticos, sociais, ambientais, entre outros. A ênfase, entretanto, não deve ser confundida com uma divisão arbitrária. Ainda que muito pouco provavelmente o pesquisador tenha domínio sobre todas essas matérias, desconsiderar o "atravessamento" dos campos citados anteriormente pode ser fatal para o objetivo de seu trabalho.

0 presente artigo propõe um esforço nesse sentido. As considerações aqui desenvolvidas foram inspiradas por uma bibliografia que possui, originalmente, enfoque diverso do problema de pesquisa exposto. Acredita-se, contudo, que prestem uma grande contribuição para o entendimento adequado e prosseguimento dessa mesma pesquisa, da forma como será esclarecido nas seções que seguem $^{2}$.

\section{Do problema de pesquisa}

Segundo publicação do Banco Mundial, já em 2000, quase a totalidade dos países participava de um ou mais pactos de integração regional (BANCO MUNDIAL. 2000) ${ }^{3}$. Entretanto, além de considerar que muitos destes acordos foram flexibilizados para o enfrentamento, especialmente, da crise econô

\footnotetext{
${ }^{2}$ Artigo originalmente desenvolvido como resultado do seminário "Território, Sociedade e Cultura", conduzido pelo prof. Dr. Álvaro Luiz Heidrich, em julho de 2012.

${ }^{3}$ Em 2003, SCHIFF e WINTER, expandem essa estimativa e afirmam que todos os países do mundo participam de pelo menos um acordo de integração regional, baseando-se nas mesmas premissas utilizadas pela publicação do Banco Mundial.
} 
mica de 2008 e suas repercussões nos anos seguintes, é preciso que se atente para os equívocos que dados como este podem gerar. Em primeiro lugar, não se deve esquecer que o Banco Mundial considera blocos de integração mesmo aqueles acordos de liberalização comercial entre dois países, os quais não necessariamente precisam compartilhar uma zona fronteiriça, o que torna o fenômeno muito amplo. Em segundo lugar, o levantamento em questão não mensura o grau de interdependência no que diz respeito ao objeto negociado dos membros do acordo de integração para considerá-lo como tal.

Quando se observa o caso das iniciativas para integração no subcontinente sul-americano é perceptível que se trata de um processo que ultrapassa os ideais de liberalização comercial, muito embora o comércio seja aqui também protagonista de muitas das negociações regionais. A coordenação entre as partes envolvidas e a tentativa de conformação de um espaço próprio das relações entre essas partes e de todas frente ao exterior deste espaço conjunto constituem processos mais propriamente integradores do que os Acordos de Livre Comércio considerados pelo Banco Mundial.

Parte desta integração mais ampla é a integração física, ou seja, a construção de infraestrutura transfronteiriça de transporte, comunicação e aproveitamento comum de recursos naturais de um grupo de países. Embora a interligação concreta, a construção de vias de acesso entre territórios, não constitua isoladamente fator de cooperação político-econômica entre os Estados, o valor da infraestrutura compartilhada como variável importante para a consolidação da integração regional é reconhecido por dirigentes sul-americanos desde a década de 1960 (CERVO, 2001; ANTUNES, 2007). A materialização no espaço do processo de integração contribuiria para concretizar intenções políticas, acordos econômicos e realidades sócioculturais.

Atente-se, entretanto, para o verbo "contribuir" utilizado no futuro do pretérito com o objetivo de ressaltar a noção hipotética dessa afirmação. Como já apontado, a integração física é, reconhecidamente, etapa necessária, embora longe de suficiente, à integração regional. No entanto, é ainda questionável se a forma como essas políticas territoriais são planejadas coaduna-se com o objetivo maior de integração regional.

A iniciativa para Integração da Infraestrutura Regional Sul-Americana (IIRSA), por exemplo, projeto que congrega obras em 12 países sul-americanos, alocadas com base no potencial de incre- mento e coordenação das cadeias produtivas, propõe-se a viabilizar o aprofundamento das relações entre os vizinhos na região, colaborando para a consecução dos objetivos integracionistas (REUNIÃO DE PRESIDENTES DA AMÉRICA DO SUL, 2000). Para avaliar, entretanto, a contribuição da iniciativa IIRSA para o processo de integração regional sulamericana, faz-se imprescindível: (a) analisar e compreender os principais objetivos e desafios da integração regional sul-americana no contexto atual para, (b) em seguida, identificar os impactos da IIRSA como foi planejada no alcance desses objetivos.

O processo de formação de blocos de países para atuação conjunta e o reforço das relações internacionais na América do Sul servem tanto a objetivos comuns quanto a específicos de cada nação. Para além dos Estados nessas duas escalas, supranacional e nacional, percebe-se que há ainda outros atores, cujas intenções interferem no processo de tomada de decisões quando da elaboração e implementação de iniciativas integracionistas. Estes atores manifestam-se ainda em diferentes escalas subnacionais - unidade ou grupo de unidades da federação, por exemplo. Estes mesmos grupos, por sua vez, podem ser parte do aparato de governo ou perseguirem interesses alheios à administração pública.

Tendo-se em mente a multiplicidade de atores e escalas de atuação a serem levadas em conta quando da pesquisa sobre processos de integração regional-internacional tratar-se-á, nas próximas seções, de enumerar algumas das considerações a serem feitas quando da execução das duas etapas identificadas acima, na esperança de que seja possível prosseguir com mais lucidez no entendimento de tal complexidade.

\section{Dos objetivos de integração}

A pesquisa sobre processos de integração e suas motivações já não se restringe aos Estados como ente monolítico, haja vista a importância em considerar os atores e as diferentes escalas em que esse processo ocorre, e ainda a existência de conflito de interesses e competição interna aos Estados e/ou paraestatais. Esse fato traduz-se, frequentemente, em uma integração em rede, heterogênea e sem capacidade de inclusão de parte representativa dos territórios-zona abarcados pela região em integração. Veja-se o caso da IIRSA: a despeito de um objetivo anunciado que engloba a integração de territórios de 12 Estados vizinhos, se propõe a fazêlo por meio da construção de eixos, "corredores territoriais", com potencial de conformação de 
cadeias produtivas e de escoamento de mercadorias através e para o exterior do continente. Esses eixos, por seu turno, privilegiam alguns pontos do território em detrimento de outros.

Sobre esses pontos proeminentes, vejamos: Renato Ortiz (2005) resgata a idéia de Saskia Sassen $^{4}$ de que o sistema capitalista já não mais pode ser analisado a partir de centros urbanos da economia-mundo e suas irradiações, mas sim, há de se considerar a interação entre diferentes pontos interdependentes. Avançando esse pensamento, Ortiz ainda questiona mesmo o conceito desses pontos, identificados como cidades-globais, atentando para o risco de ignorar-se a globalidade que atravessa também outros pontos, talvez tido como secundários em relação aos pontos "principais". Nesse sentido: restringir os interesses integracionistas sul-americanos aos interesses dos polos exportadores privilegiados pelas obras de integração física implica em um reducionismo de um ideal muito mais amplo? Ou pode-se considerar que a integração entre esses diferentes pontos é suficiente para o alcance dos ideais integracionistas?

Segundo o raciocínio de Ortiz, tratar as escalas local, nacional e global separadamente não é adequado ao entendimento da realidade. A tradução do local como origem última das raízes identitárias, como âncora das territorialidades, ignora a flexibilidade, a mobilidade, característica do cotidiano atual. Ao mesmo tempo, fica demonstrado que a correlação do local com a diversidade e do nacional com o uníssono, e sua definição nesses termos, revela-se problemática, uma vez que, colocado frente ao global, torna-se o nacional fonte de diversidade e especificidades. Adicione-se às escalas de Ortiz a escala regional no sentido supranacional a que aqui se refere: a esta tampouco é dado atribuir exclusivamente unidade ou diversidade. Paralelamente, nesses termos, tampouco faz sentido tratar regionalismo e globalização (no sentido de inserção nacional unilateral no sistema global) como alternativas opostas, estratégias de inserção incompatíveis, mas antes pelo contrário, é preciso encarálas como complementares.

Ortiz argumenta que a solução para a adequada compreensão dessas múltiplas escalas seria "tratar o espaço como um conjunto de planos atravessados por processos sociais diferenciados" (ORTIZ, 2005, p. 61). Uma vez que a integração regional é também processo social, há de se considerar o atravessamento desse processo nas diferentes escalas e considerar tal atravessamento na observação e avaliação de seus êxitos e/ou obstáculos.

Aceita essa "transversalidade espacial", é possível argumentar no sentido de que o local pode conter o interesse nacional e, portanto, também aqueles fundamentadores da integração regional internacional. Todavia, seguindo a mesma linha de raciocínio, a integração exclusiva destes determinados locais representativos dos interesses nacionais e integracionistas, ou seja, a integração em rede, se de fato representativos da escala nacional e/ou regional, deverá impactar não apenas nos pontos integrados, mas em todo o território que se espera estar representado. A transversalidade permite verificar, através dessa expectativa de reciprocidade de interferência entre as diferentes escalas, a capacidade de difusão dos resultados de uma integração-rede em uma integração-zona ${ }^{5}$.

Ainda no que diz respeito a considerações prévias à compreensão das motivações e objetivos integracionistas sul-americanos, a lógica argumentativa de Marcelo Lopes de Souza (2001) pode ser inspiradora. Ao tratar dos riscos do universalismo e relativismo cultural, o autor levanta questões que não apenas são úteis à compreensão da alteridade, do Outro com o qual não compartilhamos o mesmo imaginário, mas também auxiliam na desmistificação de discursos e noções que povoam o imaginário do qual fazemos parte.

Para o autor, adotar um posicionamento absolutamente universalista significa priorizar uma cultura em detrimento das outras ao utilizá-la como lastro para a análise de todo e qualquer contexto, enquanto o relativismo é também limitador, no sentido que nega toda e qualquer possibilidade de diálogo e, portanto, entendimento entre culturas diversas. Se aplicada ao entendimento da noção de integração e, mais especificamente, ao discurso integracionista sul-americano, a lógica que opõe universalismo e relativismo traduzir-se-ia em, respectivamente: por um lado, entender os objetivos da integração de maneira idealizada, com parâmetros em um modelo quasemítico do que se esperaria de uma integração regional completa e, a partir desse modelo "universal", comparado com os avanços nessa direção previamente concebida, tentar mensurar o grau de sucesso das iniciativas de integração reais, efetivadas; por outro lado, encerrar o processo e discurso de integração em si mesmo, apenas considerando as propostas das iniciativas e estritamente $o$ cumprimento destas para a análise do progresso da integração na região.

\footnotetext{
${ }^{4}$ Renato Ortiz faz referência, mais especificamente, ao trabalho da autora "The global city: New York, London, Tokyo", de 1991.

${ }^{5}$ As expressões integração-rede e integração-zona são aqui utilizadas à imagem das noções de território-rede e território-zona como tratados em Haesbaert (2004).
} 
A fim de entender um processo de integração regional internacional é necessário que se compreenda as motivações das partes para o engajamento em tal empreitada. Só após definidas as razões e interesses dos Estados (e presentes nos Estados) signatários de um Acordo de Livre Comércio, por exemplo, será possível a avaliação das medidas adotadas, se eficientes ou não, para a obtenção dos objetivos propostos. 0 grau de sucesso de um empreendimento só pode ser mensurado com relação à finalidade estabelecida.

Entretanto, admitir a necessidade de se evitar a comparação com tipos ideais - analisar o progresso do Mercosul comparando-o com a União Europeia, por exemplo - não tira a validade de tomar em conta na avaliação alguma expectativa que ultrapasse ao que foi objetivamente proposto. Esperar-se de um processo intitulado de "integração regional" alguns predicados que extrapolam a mera cooperação em aspectos comerciais não será condenável, nem deverá surpreender, mesmo que o contrato assinado pelas partes que se pronunciam como engajadas em um processo de integração apenas se manifeste relativamente ao comércio. A exemplo do universalismo e do relativismo como tratados por Souza, ambas vias de interpretação são, portanto, complementares, e não excludentes, a "dicotomia - dois extremos opostos e inconciliáveis - cede lugar, destarte, à bilpolarização" (SOUZA, 2001, p. 158).

\section{Dos atores territorializantes}

Compreendido o tipo de integração, a profundidade almejada para o processo, a que se faz alusão quando o enfoque recai sobre o regionalismo sul-americano, através da análise histórica das iniciativas implementadas e dos discursos propagados, é possível então que se proceda à segunda etapa da pesquisa proposta: verificar se a iniciativa em questão, a IIRSA, da forma como planejada, tem capacidade para auxiliar na realização da integração aspirada. Para tanto, retome-se neste ponto a percepção de que, não obstante os acordos integracionistas sejam firmados em última instância pelos ou com aval dos Estados, os atores envolvidos não apenas agem com motivações nacionais, mas antes estão imbuídos de interesses diversos, públicos e privados. Partindo-se da aceitação dessa hipótese, é por meio da observação desses atores que se fará possível verificar se estratégia (IIRSA) e objetivo (integração) são condizentes.
A concepção de território como resultante de relações de poder justifica a análise do processo de conformação do território a partir dos atores e das ações empreendidas por estes. Nesse sentido, Di Méo (2006) fala do território como um "sistema de ações".É também nessa direção que acena Romain Lajarge (2009) quando advoga que, uma vez admitido ser necessária ação para que haja territorialização, é por meio da compreensão desse agir que se pode avançar na compreensão do problema do território (território, territorialização e territorialidade).

Ademais de suas reflexões sobre como avançar na compreensão da questão territorial por meio da apreensão das ações e da intenção dos atores ao agir, Lajarge questiona se, a fim de compreender-se a territorialização, não seria também necessário interpretar a ação que torna a territorialização possível. 0 autor lembra que:

\footnotetext{
"(...) para que a ação seja possível, é necessário que certas condições prévias a ação sejam de conhecimento do ator, que o ator tenha capacidade de ativar aquilo de que conhece e, enfim, que as interações na qual se encontra $o$ ator o autorizem a desenvolver sua ação" (LAJARGE, 2009, p. 202, tradução livre) ${ }^{6}$.
}

Depreende-se daí, para além da noção de que não há territorialização sem ação, a ideia de territorialização como um encadeamento, da existência de um material, um contexto prévio do qual parte o agir territorializante. Essa elucidação sobre o potencial de conhecer o contexto e ser capaz de utilizá-lo deixa margem para que se liberte, talvez, de uma percepção determinista ou absolutamente estável das relações que constituem o território. Explica-se: se para que a ação seja realizada considera-se um momento anterior de territorialização, território e territorialidade, de certa maneira, como insumos de territorialização, é possível que o resultado da intenção do primeiro territorializador seja utilizado (acionado) para finalidades e intenções diferentes.

Aplicada ao caso aqui destacado, a consideração de um encadeamento de ações territorializantes por atores diferentes permite pensar que, por exemplo, muito embora um projeto de construção de rodovia privilegie determinada atividade econômica e leve em consideração mais interesses privados do que públicos e/ou coletivos, o resultado dessa ação pode vir a ser instrumentalizado

\footnotetext{
${ }^{6}$ No original: "(...) pour que l'action soit possible, il est donc nécessaire que certaines conditions préalables à l'action soit connues par l'acteur, que l'acteur soit capacité de rendre actif ce qu'il connâit et enfin que les interactions dans lesquelles se trouve cet acteur autorisent qu'il déroule son action" (LAJARGE, 2009, p. 202).
} 
para outras finalidades, muitas vezes não previstas, porém, nem por isso, menos convergentes com o objetivo original. Tal qual a "ritualização" dos espaços urbanos descrita por Fernandes (1992, p. 88), é possível especular sobre a possibilidade de a apropriação das vias de integração por parte da sociedade civil ser uma forma para que esse ator coletivo seja também incluído, ou melhor, inclua-se e usufrua do processo de integração na América do Sul.

O componente social do processo de integração, dessa forma, deixa de ser analisado apenas como ente passivo, no sentido de que apenas sofre as ações territorializantes integradoras dos dirigentes políticos e/ou daqueles que tem acesso e influência sobre o processo decisório por razões econômicas, por exemplo. Igualmente, admite-se algo que pode parecer uma obviedade, mas não raro é ignorado: as fases de delimitação dos objetivos, de planejamento e resultado das ações não tem correspondência automática. Assim como o planejamento inadequado pode não prestar-se ao objetivo proposto, mesmo a consecução correta do que foi planejado, pode gerar resultados derivados imprevistos.

\section{Considerações finais}

Este artigo buscou apontar, quase em caráter ensaístico, algumas considerações a ter-se em mente quando da pesquisa em integração regional. Muito embora tenha se atido ao caso da integração sul-americana e da estratégia integracionista conduzida por meio da iniciativa para Integração da Infraestrutura Regional Sul-Americana, acreditase que as ideias expostas possam ser pertinentes também no estudo de outras ações públicas e políticas territoriais com potencial de incidência e elaboração a partir de interesses em múltiplas escalas. Para além, resta a consciência de que, sem prejuízo da validade do presente trabalho, cada uma dessas ideias deverá ainda ser amadurecida e aprofundada.

\section{Referências}

ANTUNES, José. Infra-estrutura na América do Sul: situação atual, necessidades e complementaridades possíveis com o Brasil. Brasília: CEPAL, 2007.

BANCO MUNDIAL. Trade Blocs. A World Bank Policy Research Report. Nova Iorque: Oxford University, 2000. Disponível em: <http://go.worldbank.org/O5F1YIQJ80 $>$. Acesso em: 24 mai. 2012.

CERVO, A. Luiz. Relações Internacionais da América Latina: velhos e novos paradigmas. Brasília: Funag/Ibri,
2001.

DI MÉO, Guy. Les territoies de l'action. In: Bulletin de la Société géographique de Liège. Liège, $\mathrm{n}^{\circ} 48,2006$, pp. 7-17.

FERNANDES, A. Teixeira. Espaço social e suas representações. In: Revista da Faculdade de Letras: Sociologia. Porto, Universidade do Porto, vol. 2, 1992, pp. 61-99.

HAESBAERT, Rogério. 0 mito da desterritorialização: do "fim dos territórios" à multiterritorialidade. Rio de Janeiro: Bertrand Brasil, 2004.

LAJARGE, R. Pas de territorialisation sans action (e vice versa?). In: VANIER, M. Territoires, territorialité, territorialisation. Rennes: presses Universitaires de Rennes, 2009, pp. 193-204.

ORTIZ, Renato. Um outro território. Ensaios sobre a mundialização. São Paulo: Olho d'Água, 2005.

REUNIÃO DE PRESIDENTES DA AMÉRICA DO SUL. Comunicado de Brasília. Brasília, Brasil, 31 de agosto e $1^{\circ}$ de setembro de 2000. Disponível em: <http:// www.iirsa.org/>. Acesso em: 25 abr. 2012.

SCHIFF, Maurice; WINTER, L. Alan. Regional integration and development. Nova Iorque: Oxford University, 2003. Disponível em: <http://www.worldbank.org/>. Acesso em: 24 mai. 2012.

SOUZA, Marcelo Lopes de. Território do Outro, problemática do Mesmo? 0 princípio da autonomia e a superação da dicotomia universalismo ético versus relativismo cultural. In: ROSENDAHL, Zeny e CORRÊA, Roberto Lobato (orgs.). Religião, identidade e território. Rio de Janeiro: EdUERJ, 2001, pp. 145-176. 
Iniciative For South America Regional Infrastructure Integration (IIRSA): Preliminar considerations about objectives, actors and scales of action

Abstract - This paper aims to outline some important preliminary considerations to the analysis of international integration processes, developed out of such notions as the "space transversality", the "binomial" universalism-relativism and the correlation "action-territorialization". It is believed, however, that the ideas developed focusing South American integration and, more specifically, the initiative for the Integration of Regional Infrastructure in South America, can also be useful for any research on territorial policies with preparation and results at multiple scales.

Keywords: IIRSA. South American Integration. Space Transversality. Universalism-relativism. Actionterritorialization. 